\title{
Economic burden of illness among US patients experiencing fracture nonunion
}

This article was published in the following Dove Press journal:

Orthopedic Research and Reviews

9 March 2013

Number of times this article has been viewed

\author{
Ning $\mathrm{Wu}^{\prime}$ \\ Yuan-chi Lee' \\ Daniel Segina ${ }^{2}$ \\ Hallie Murray ${ }^{3}$ \\ Teresa Wilcox' \\ Luke Boulanger ${ }^{\prime}$ \\ 'United BioSource Corporation, \\ Lexington, MA, USA; ${ }^{2}$ Department \\ of Orthopaedics, Holmes Regional \\ Trauma Center, Melbourne, FL, USA; \\ ${ }^{3}$ Biomet Spine and Bone Healing \\ Technologies, Parsippany, NJ, USA
}

Correspondence: Ning Wu

United BioSource Corporation,

430 Bedford Street, Suite 300, Lexington

Office Park, Lexington, MA, USA 02420

$\mathrm{Tel}+\mathrm{I} 7819600343$

Fax + I81 761 04I7

Email ning.wu@unitedbiosource.com
Objectives: To compare economic outcomes in a real-world study of patients with fracture nonunion receiving non-invasive electrical bone growth stimulation (EBGS), low-intensity pulsed ultrasound stimulation (LIPUS), or other non-stimulation fracture management interventions (No-stim).

Methods: Medical and pharmacy claims from a US commercially-insured population were analyzed to select adult patients newly diagnosed with a fracture nonunion between July 2006 and September 2009. The date of initial nonunion diagnosis was set as the index date. Three cohorts were constructed based on the first treatment prescribed post index date: EBGS, LIPUS, or No-stim. Baseline demographics, clinical characteristics, and health care costs 9 months before and 1 year after the index date were assessed. Multivariate regression analyses were performed to compare health care costs between cohorts in the post index period.

Results: 11,628 patients (mean age 45.4 years; $45.7 \%$ males) with a fracture nonunion were identified within the three treatment groups (EBGS: 29.5\%, LIPUS: $12.3 \%$, and No-stim: $58.2 \%$ ). In the post-index period, EBGS patients were significantly less likely to receive fracture-related treatments when compared to the LIPUS $(33.6 \%$ vs $42.2 \%, P<0.01)$ and the No-stim $(33.6 \%$ vs $60.3 \%, P<0.01)$ cohorts. Additionally, after adjusting for demographic and clinical characteristics, the EBGS cohort had significantly lower predicted health careassociated costs 1 year post index date when compared to the LIPUS (mean: \$21,632 vs \$23,964, $P<0.01$ ) and the No-stim (mean: $\$ 21,632$ vs $\$ 23,843, P<0.01$ ) cohorts. Furthermore, the predicted fracture-related costs (FRC) of EBGS patients were also significantly lower than the FRC of the LIPUS (mean: $\$ 9100$ vs $\$ 10,255, P<0.01$ ) and the No-stim (mean: $\$ 9100$ vs $\$ 10,354, P<0.01)$ patients.

Conclusion: In a real-world setting, EBGS is a more cost-effective fracture nonunion treatment across a variety of fracture locations when compared to LIPUS or No-stim. Fracture nonunion patients receiving EBGS had lower total health care resource use and overall costs as compared to LIPUS or No-stim.

Keywords: electrical bone growth stimulation, low-intensity pulsed ultrasound stimulation, nonunion, fracture, health care utilization, economic burden

\section{Introduction}

Approximately 7.9 million patients sustain fractures in the United States annually, and up to $10 \%$ go on to have impaired bone healing resulting in a delayed union or a nonunion. ${ }^{1}$ The distinction between a delayed union and a nonunion has been redefined over the years. A delayed union is currently defined as a fracture that has slower than expected bone healing. ${ }^{2}$ Prior to 1998, the Food and Drug Administration (FDA) defined a nonunion as a fracture 9 months post-injury that shows no visibly 
progressive signs of healing for a minimum of 3 months. ${ }^{3-5}$ In 1998, the FDA's Orthopedics and Rehabilitation Device Advisory Panel revised the definition of a nonunion to be a fracture that shows no visibly progressive signs of healing. . $^{3,6}$ This new definition has no timeframe restrictions associated with the determination of a nonunion.

Not all fractures are alike, and fracture healing has been shown to vary substantially depending on the fracture location. Non-operatively treated clavicular fractures have a reported nonunion rate of $6.2 \%$, but that rate differs by the fracture site: $8.3 \%$ for medial end fractures, $4.5 \%$ for diaphyseal fractures, and $11.5 \%$ for lateral end fractures. ${ }^{7}$ Scaphoid fractures have an approximate nonunion rate of $10 \%$, but the risk of nonunion can be as high as $55 \%$ when the fracture is displaced. ${ }^{8}$ Moreover, depending on the specific fracture characteristics and the initial fracture management, $7 \%-28 \%$ of fractures of the proximal fifth metatarsal result in nonunion. ${ }^{9}$ Differences in vascularity at the fracture site, fracture severity, and patient comorbidities affect the ability of different fractures to heal, resulting in the different reported nonunion rates. ${ }^{10-14}$ Consequently, individualized fracture management is required to promote fracture healing.

Common methods for treating fracture nonunions include surgical repair, allografts, synthetic bone grafts, autogenous bone grafts, recombinant bone morphogenetic proteins, and amputation when other treatment options have failed to induce healing. ${ }^{15-18}$ Non-invasive therapies, including electrical bone growth stimulation (EBGS) and low-intensity pulsed ultrasound stimulation (LIPUS), are FDA regulated Class III medical devices approved for the treatment of fracture nonunions. ${ }^{14,16,19-23}$ The first EBGS device received approval for the treatment of fracture nonunions in 1979; since then three additional competitive non-invasive EBGS device systems and one LIPUS device have also received approval for the treatment of fracture nonunions. ${ }^{19-25}$ With over 30 years of clinical use, EBGS has proven to be a safe and effective treatment for the management of fracture nonunions. ${ }^{26-39}$

In today's health care environment, understanding the economic evaluation of different treatment options is important. In 2006, bone growth stimulation represented a \$500 million market in the US for fracture management as a result of the significant economic burden associated with fracture nonunions. ${ }^{40}$ An economic review conducted by Kanakaris and Giannoudis reported that the average direct costs for treating humeral, femoral, and tibial fracture nonunions were $£ 15,566, £ 17,200$, and $£ 16,330$, respectively, in the United Kingdom in 2007. Converted to US dollars, these costs are equivalent to $\$ 31,132, \$ 34,400$, and $\$ 32,660$, respectively. ${ }^{41}$ While existing clinical literature supports the efficacy and safety of non-invasive EBGS therapy in the treatment of fracture nonunions, ${ }^{26-39}$ the economic data supporting its use in the US is sparse. Therefore, the objective of this study was to evaluate the real-world costeffectiveness of EBGS in the treatment of fracture nonunions. This study compares the demographic differences, clinical characteristics, and treatment patterns of patients receiving EBGS, LIPUS, or no stimulation (No-stim) treatment for the management of their fracture nonunions and the health care resource use and costs associated with these different treatment options.

\section{Methods}

\section{Data source and sample selection}

This retrospective study utilized administrative claims data from the Truven Health Analytics MarketScan Commercial Insurance Databases ${ }^{42}$ from October 2005 through September 2010. Patients were included in the study if they had at least one medical claim with associated diagnosis suggesting fracture nonunion (International Classification of Diseases, Ninth Revision, Clinical Modification [ICD-9-CM]: 733.82) between July 2006 and September 2009. Patients may have had multiple medical claims with associated diagnosis codes suggesting fracture nonunion for the initial diagnosis, subsequent treatment, and follow-up visits; therefore, the date of the first such medical claim was set as the index date. Patients were required to have at least one medical claim related to the diagnosis of their fracture in the 9 months prior to the index date. Only patients with claims for fractures of the appendicular system were included. Additional inclusion criteria required patients to be between 18-64 years old on the index date (this age range represents a commercially insured patient population; patients 65 years old or older were excluded as these patients are typically insured by Medicare and Medicaid), and have a minimum of 9 months of insurance eligibility prior to and 12 months following the index date. Patients were excluded if they had claims suggesting cancer metastasis (ICD-9-CM: 198.5), malignant tumor of bone (ICD-9-CM: 170.xx), fracture nonunion, use of EBGS or LIPUS, or fractures in multiple locations during the 9 months before the index date (Figure 1).

Three cohorts were created based on the first treatment that patients received within the 12 months following the index date: EBGS, LIPUS, and No-stim. The use of EBGS was identified if a medical claim had an associated Current Procedural Terminology (CPT) code of 20974 or Healthcare 


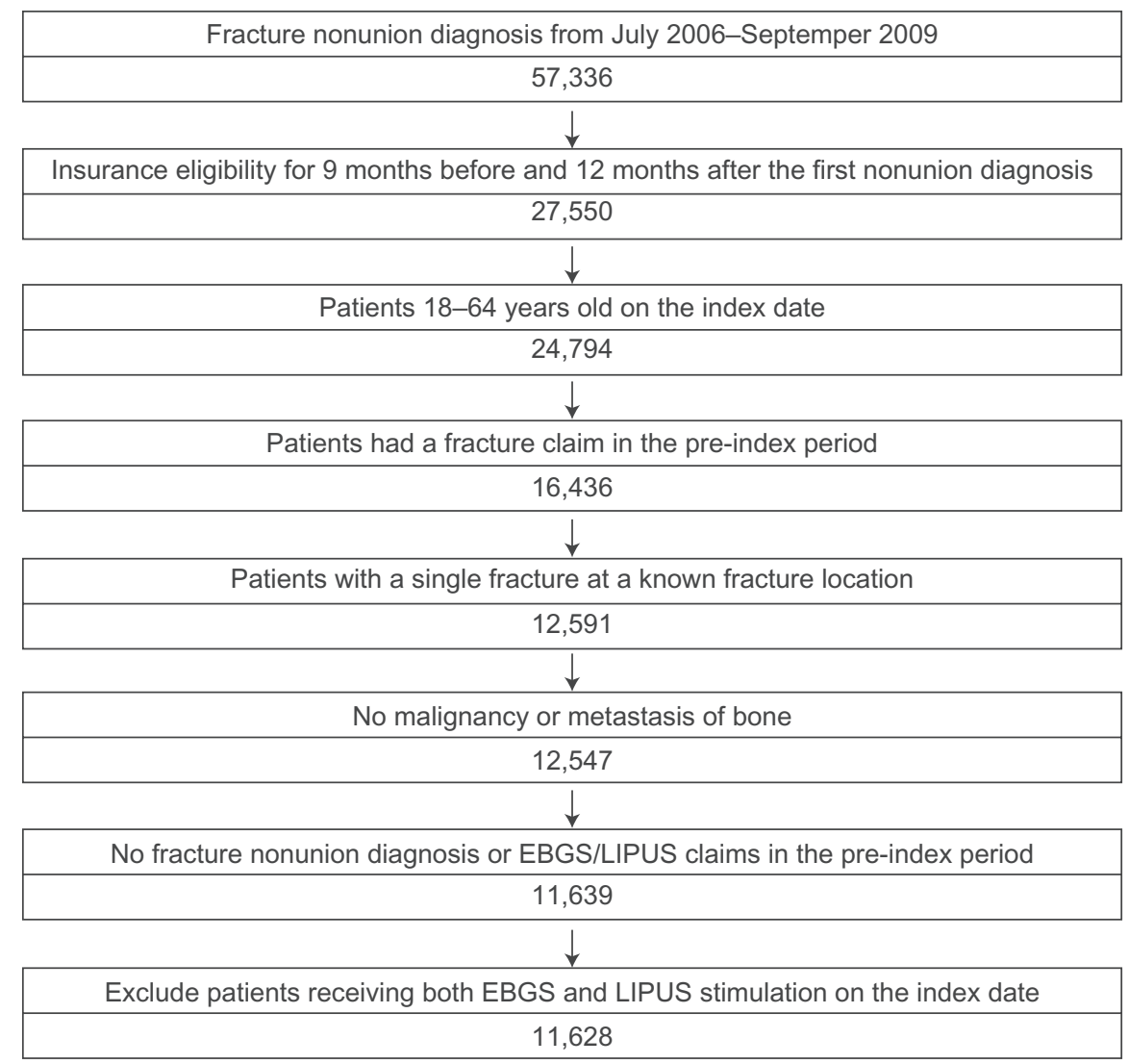

Figure I Selection flow chart for patient eligibility.

Abbreviations: EBGS, electrical bone growth stimulation; LIPUS, low-intensity pulsed ultrasound stimulation.

Common Procedure Coding System (HCPCS) code of E0747. Use of LIPUS was identified if a claim had an associated CPT code of 20979 or HCPCS code of E0760. The No-stim cohort included those patients with fracture nonunion diagnosis that did not receive EBGS or LIPUS after the index date.

\section{Study measures}

Demographic parameters including age, gender, geographic region of US residence (Northeast, North Central, South, West, and unknown), and insurance plan type (health maintenance organization, preferred provider organization, comprehensive, point of service, exclusive provider organization, and consumer-directed health plans) are listed in Table 1. Comorbidities and risk factors for fracture nonunion were assessed based on medical and pharmacy claims in the 9 months before the index date. The burden of chronic diseases was measured by the Charlson Comorbidity Index (CCI). ${ }^{43,44}$ Fracture characteristics including open vs closed, fracture location, and the time between initial fracture and nonunion diagnosis were also reported. Clinical outcomes were neither reported nor available from the database for analysis.
Health care costs for the 9 months before and the 12 months after the index date were evaluated. Total health care costs included the costs associated with inpatient care, outpatient care, and medication use. Fracture-related costs included all claims associated with services required to diagnose and treat the patient's fracture. Pharmacy-related costs were excluded from the fracture-related costs as there are no specific medications designated for the treatment of a fracture. All costs were adjusted for inflation using the Consumer Price Index and standardized to 2011 US dollars so that cost measures from different years would be comparable. ${ }^{45}$

\section{Statistical analysis}

Descriptive statistics for demographics, comorbidities, treatment patterns, fracture locations, and post-index health care and fracture-related costs were compared among the three different treatment cohorts. Percentages were reported for categorical variables, while the mean and standard deviation were reported for continuous variables. A Student's $t$-test was used to detect differences in age and days between initial fracture and nonunion diagnosis; a $\chi^{2}$ test was used to detect 
Table I Demographics and comorbidities of the three treatment cohorts: EBGS, LIPUS and No-stim

\begin{tabular}{|c|c|c|c|c|c|c|c|c|c|}
\hline & \multicolumn{6}{|c|}{ Treatment cohorts } & \multicolumn{3}{|l|}{$P$-values } \\
\hline & \multicolumn{2}{|c|}{$\begin{array}{l}\text { EBGS } \\
(\mathrm{N}=3,430) \\
\end{array}$} & \multicolumn{2}{|c|}{$\begin{array}{l}\text { LIPUS } \\
(\mathrm{N}=1,434)\end{array}$} & \multicolumn{2}{|c|}{$\begin{array}{l}\text { No-stim } \\
(\mathbf{N}=6,764)\end{array}$} & \multirow[t]{2}{*}{$\begin{array}{l}\text { EBGS vs } \\
\text { LIPUS }\end{array}$} & \multirow[t]{2}{*}{$\begin{array}{l}\text { EBGS vs } \\
\text { No-stim }\end{array}$} & \multirow[t]{2}{*}{$\begin{array}{l}\text { LIPUS vs } \\
\text { No-stim }\end{array}$} \\
\hline & $\mathbf{N}$ & $(\%)$ & $\mathbf{N}$ & $(\%)$ & $\mathbf{N}$ & $(\%)$ & & & \\
\hline Age (years) & & & & & & & 0.51 & $<0.01$ & $<0.01$ \\
\hline I8-24 & 345 & $(10.1)$ & 133 & (9.3) & 978 & $(14.5)$ & & & \\
\hline $25-34$ & 316 & $(9.2)$ & 118 & $(8.2)$ & 708 & $(10.5)$ & & & \\
\hline $35-44$ & 597 & $(17.4)$ & 242 & $(16.9)$ & 1,137 & $(16.8)$ & & & \\
\hline $45-54$ & $\mathrm{I}, 084$ & $(31.6)$ & 456 & $(31.8)$ & $\mathrm{I}, 888$ & $(27.9)$ & & & \\
\hline $55-64$ & I,088 & $(31.7)$ & 485 & $(33.8)$ & 2,053 & $(30.4)$ & & & \\
\hline Gender & & & & & & & 0.77 & $<0.01$ & $<0.01$ \\
\hline Male & 1,379 & $(40.2)$ & 583 & $(40.7)$ & 3,350 & $(49.5)$ & & & \\
\hline Female & $2,05 I$ & $(59.8)$ & 851 & (59.3) & 3,414 & $(50.5)$ & & & \\
\hline Insurance plan type & & & & & & & 0.06 & 0.08 & $<0.01$ \\
\hline Comprehensive & 104 & (3.0) & 31 & $(22)$ & 265 & (3.9) & & & \\
\hline EPO & 16 & $(0.5)$ & 8 & $(0.6)$ & 30 & $(0.4)$ & & & \\
\hline $\mathrm{HMO}$ & 503 & $(14.7)$ & 192 & $(13.4)$ & 1,003 & $(14.8)$ & & & \\
\hline POS & 339 & $(9.9)$ & 143 & $(10.0)$ & 584 & $(8.6)$ & & & \\
\hline PPO & 2,254 & $(65.7)$ & 995 & $(69.4)$ & 4,542 & $(67.1)$ & & & \\
\hline POS w/capitation ${ }^{\mathrm{a}}$ & 25 & $(0.7)$ & 3 & $(0.2)$ & 42 & $(0.6)$ & & & \\
\hline CDHP & 86 & $(2.5)$ & 28 & $(2.0)$ & 146 & $(2.2)$ & & & \\
\hline Missing/unknown & 103 & $(3.0)$ & 34 & $(2.4)$ & 152 & $(2.2)$ & & & \\
\hline Region & & & & & & & $<0.01$ & $<0.01$ & $<0.01$ \\
\hline Northeast & 481 & $(14.0)$ & $|3|$ & $(9.1)$ & 640 & $(9.5)$ & & & \\
\hline North Central & 769 & $(22.4)$ & 304 & $(21.2)$ & 1,944 & $(28.7)$ & & & \\
\hline South & $|, 48|$ & $(43.2)$ & 739 & $(51.5)$ & 2,744 & $(40.6)$ & & & \\
\hline West & 625 & $(18.2)$ & 223 & $(15.6)$ & 1,309 & $(19.4)$ & & & \\
\hline Unknown & 74 & $(2.2)$ & 37 & $(2.6)$ & 127 & $(1.9)$ & & & \\
\hline Charlson Comorbidity Index & & & & & & & 0.47 & $<0.01$ & 0.01 \\
\hline $\mathrm{CCl}=0$ & 2,394 & $(69.8)$ & 1,012 & $(70.6)$ & 5,029 & $(74.3)$ & & & \\
\hline $\mathrm{CCl}=\mathrm{I}$ & 344 & $(10.0)$ & 154 & $(10.7)$ & 567 & $(8.4)$ & & & \\
\hline $\mathrm{CCl}=2$ & 443 & $(12.9)$ & 163 & $(1 \mathrm{l} .4)$ & 685 & $(10.1)$ & & & \\
\hline $\mathrm{CCl}>3$ & 249 & $(7.3)$ & 105 & $(7.3)$ & 483 & $(7.1)$ & & & \\
\hline \multicolumn{10}{|c|}{ Comorbidities of fracture nonunion } \\
\hline Diabetes & 479 & $(14.0)$ & 183 & $(12.8)$ & 742 & $(11.0)$ & 0.26 & $<0.01$ & 0.05 \\
\hline Osteoporosis & 173 & $(5.0)$ & 66 & $(4.6)$ & 271 & $(4.0)$ & 0.52 & 0.02 & 0.30 \\
\hline Malnutrition & 3 & $(0.1)$ & 4 & $(0.3)$ & 20 & $(0.3)$ & 0.11 & 0.04 & 0.92 \\
\hline Anemia & 234 & $(6.8)$ & 121 & $(8.4)$ & 498 & (7.4) & 0.05 & 0.32 & 0.16 \\
\hline \multicolumn{10}{|c|}{ Risk factors of fracture nonunion } \\
\hline Smoking & 7 & $(0.2)$ & 5 & $(0.3)$ & 23 & $(0.3)$ & 0.35 & 0.23 & 0.96 \\
\hline Excessive alcohol drinking & 27 & $(0.8)$ & 5 & $(0.3)$ & 57 & $(0.8)$ & 0.09 & 0.77 & 0.05 \\
\hline Received chemotherapy & 79 & $(2.3)$ & 43 & $(3.0)$ & 142 & $(2.1)$ & 0.16 & 0.50 & 0.04 \\
\hline Received steroid & 651 & $(19.0)$ & 308 & $(21.5)$ & $\mathrm{I}, 254$ & $(18.5)$ & 0.05 & 0.59 & 0.01 \\
\hline Received NSAIDs & 940 & $(27.4)$ & 370 & $(25.8)$ & 1,563 & $(23.1)$ & 0.25 & $<0.01$ & 0.03 \\
\hline
\end{tabular}

Note: aCapitation pays a physician or group of physicians a set amount for each enrolled person assigned to them, per period of time, whether or not that person seeks care. Abbreviations: $\mathrm{CCl}$, Charlson Comorbidity Index; CDHP, consumer-directed health plan; EBGS, electrical bone growth stimulation; EPO, exclusive provider organization; $\mathrm{HMO}$, health maintenance organization; LIPUS, low-intensity pulsed ultrasound stimulation; No-stim, other non-stimulation fracture management interventions; NSAIDs, non-steroidal anti-inflammatory drugs; POS, point of service; PPO, preferred provider organization.

differences for categorical variables; and a non-parametric Wilcoxon test was used to detect differences for CCI scores and health care and fracture-related costs. A generalized linear regression model (GLM) assuming gamma distribution and $\log$ link function was utilized to compare the total and fracture-related health care costs between treatment cohorts while controlling for between-cohort differences in patient demographics and baseline clinical characteristics. Because it is difficult to interpret the log-transformed regression coefficients from the GLM, predicted health care costs and the marginal effect of treatment were estimated. Specifically, the predicted costs for EBGS were estimated by applying the regression coefficients derived from the GLM to the covariates included in the model, and setting 
EBGS to 1 and LIPUS to 0 while other covariates remained constant. Similarly, the predicted costs for LIPUS treatment were estimated by setting EBGS to 0 and LIPUS to 1, while the predicted costs for No-stim treatment were estimated by setting both EBGS and LIPUS to 0. An analysis of the marginal effects of treatment demonstrated how total and fracture-related health care costs are predicted to change as treatment changes from No-stim to EBGS to LIPUS.

\section{Results}

Among the commercially insured individuals in the dataset, 57,336 patients had at least one claim for fracture nonunion from July 2006 to September 2009. After applying the inclusion/exclusion criteria, 11,628 patients were selected for further study analysis (Figure 1): 3430 patients (29.5\%) were in the EBGS cohort, 1434 patients (12.3\%) were in the LIPUS cohort, and 6764 patients $(58.2 \%)$ were in the No-stim cohort.

Basic patient demographics found that the average patient age was 45.4 years old (standard deviation: 13.4 ), $45.7 \%$ were males, $67.0 \%$ were enrolled in preferred provider organization plans, and $42.7 \%$ resided in the southern United States. Overall, the EBGS and LIPUS cohorts were similar in the distribution of age, gender, and type of patient insurance plan. However, both stimulation cohorts had more female patients and a higher average age than the No-stim cohort (Table 1).

Patients within the different treatment groups were also evaluated for fracture risk factors and comorbidities as these factors have been previously shown to have a negative impact on the success of bone healing. ${ }^{10-14}$ Diabetes was the most common condition among the comorbidities associated with increased risk of fracture nonunion (Table 1). The proportion of patients with diabetes was significantly higher in the EBGS cohort when compared to the No-stim cohort $(14.0 \%$ vs $11.0 \%, P<0.01$ ), but was not significantly different between the EBGS and LIPUS cohorts $(14.0 \%$ vs $12.8 \%, P=0.26)$. The proportion of patients receiving non-steroidal antiinflammatory drugs was significantly higher in the EBGS cohort $(27.4 \%$ vs $23.1 \%, P<0.01)$ and the LIPUS cohort (25.8\% vs $23.1 \%, P=0.03)$ when compared to the No-stim cohort. In addition, both the EBGS (CCI $=0: 69.8 \%$ vs $74.3 \%, P<0.01)$ and the LIPUS (CCI $=0: 70.6 \%$ vs $74.3 \%$, $P=0.01)$ cohorts were less likely to have low CCI scores when compared to the No-stim cohort.

Basic fracture characteristics found that tarsal and metatarsal fractures were the most common nonunion fractures treated; the average time between initial fracture and nonunion diagnosis was $130-136$ days; and $3.6 \%$ of the initial fractures were open fractures. The No-stim cohort had a significantly higher proportion of patients with open fractures than the EBGS (4.4\% vs $2.7 \%, P<0.01)$ and the LIPUS $(4.4 \%$ vs $1.8 \%, P<0.01)$ cohorts (Table 2$)$. Additionally, although the EBGS and LIPUS cohorts had a comparable distribution of fractures treated by bone location $(P=0.17)$, the distribution was significantly different when compared to the No-stim cohort (both $P<0.01$ ).

In the 9 months prior to the index date, the EBGS and LIPUS cohorts had a similar number of fracture-related interventions $(60.1 \%$ vs $57.5 \%, P=0.10)$. The No-stim cohort, however, had significantly fewer fracture-related interventions compared to either the EBGS $(60.1 \%$ vs $48.0 \%$, $P<0.01)$ or the LIPUS $(57.5 \%$ vs $48.0 \%, P<0.01)$ cohorts (Table 2). The most common fracture-related treatment was the application of a cast/splint. The EBGS and LIPUS cohorts had significantly more patients receiving a cast/ splint to manage their fractures than the No-stim cohort (EBGS vs No-stim: $32.3 \%$ vs $24.3 \%, P<0.01$; LIPUS vs No-stim: $31.0 \%$ vs $24.3 \%, P<0.01$ ). Open reduction with internal fixation was the most common invasive treatment. The EBGS and LIPUS cohorts had a similar proportion of open reduction procedures $(20.8 \%$ vs $19.1 \%, P=0.19)$. However, both had a significantly higher proportion of open reduction procedures compared to the No-stim cohort (EBGS vs No-stim: $20.8 \%$ vs $14.5 \%, P<0.01$; LIPUS vs No-stim: $19.1 \%$ vs $14.5 \%, P<0.01)$.

During the 12-month post-index period, the proportion of fracture-related procedures was significantly less in the EBGS cohort than in the No-stim $(33.6 \%$ vs $60.3 \%$, $P<0.01)$ and LIPUS (33.6\% vs $42.2 \%, P<0.01)$ cohorts. Additionally, the LIPUS cohort also had significantly fewer fracture-related interventions when compared to the No-stim cohort (42.2\% vs 60.3\%, $P<0.01$ ) (Table 2$)$. Bone grafting was the most common fracture-related treatment in the postindex period. The proportion of patients that underwent bone grafting procedures was significantly lower in the EBGS cohort than in the LIPUS $(16.2 \%$ vs $22.2 \%, P<0.01)$ or the No-stim $(16.2 \%$ vs $31.8 \%, P<0.01)$ cohorts. Similarly, the LIPUS cohort had significantly fewer patients treated by bone grafting procedures when compared to the No-stim cohort (22.2\% vs $31.8 \%, P<0.01)$. The other documented nonstimulation fracture management interventions included cast/ splint, application of external fixation device, closed reduction with and without internal fixation, open reduction with and without internal fixation, and arthroscopy.

The total health care costs in the 9 months prior to the index date were significantly higher in the EBGS 
Table 2 Characteristics of fracture-related treatments in the different treatment cohorts

\begin{tabular}{|c|c|c|c|c|c|c|}
\hline & \multicolumn{3}{|c|}{ Treatment cohorts } & \multicolumn{3}{|l|}{$P$-values } \\
\hline & $\begin{array}{l}\text { EBGS } \\
(N=3,430)\end{array}$ & $\begin{array}{l}\text { LIPUS } \\
(N=1,434)\end{array}$ & $\begin{array}{l}\text { No-stim } \\
(\mathrm{N}=6,764)\end{array}$ & $\begin{array}{l}\text { EBGS vs } \\
\text { LIPUS }\end{array}$ & $\begin{array}{l}\text { EBGS vs } \\
\text { No-stim }\end{array}$ & $\begin{array}{l}\text { LIPUS vs } \\
\text { No-stim }\end{array}$ \\
\hline \multicolumn{7}{|l|}{ and nonunion, mean (SD) } \\
\hline Open fracture, $\mathrm{N}(\%)$ & $93(2.7)$ & $26(1.8)$ & $299(4.4)$ & 0.06 & $<0.01$ & $<0.01$ \\
\hline Fracture location, N (\%) & & & & 0.17 & $<0.01$ & $<0.01$ \\
\hline Clavicle & $207(6.0)$ & $96(6.7)$ & $565(8.4)$ & & & \\
\hline Humerus & $180(5.2)$ & $65(4.5)$ & $431(6.4)$ & & & \\
\hline Radius and ulna & $210(6.1)$ & $97(6.8)$ & $688(10.2)$ & & & \\
\hline Carpal & $26 \mid(7.6)$ & $107(7.5)$ & $993(14.7)$ & & & \\
\hline Metacarpal & $47(1.4)$ & $8(0.6)$ & $146(2.2)$ & & & \\
\hline Phalanges of hand & $29(0.8)$ & II (0.8) & $363(5.4)$ & & & \\
\hline Neck of femur & $35(1.0)$ & $13(0.9)$ & $213(3.1)$ & & & \\
\hline Other parts of femur & $78(2.3)$ & $47(3.3)$ & $163(2.4)$ & & & \\
\hline Tibia and fibula & $332(9.7)$ & $160(11.2)$ & $374(5.5)$ & & & \\
\hline Ankle & $275(8.0)$ & $133(9.3)$ & $690(10.2)$ & & & \\
\hline Tarsal and metatarsal bones & $\mathrm{I}, 66 \mathrm{I}(48.4)$ & $645(45.0)$ & $\mathrm{I}, 609(23.8)$ & & & \\
\hline Phalanges of foot & $76(2.2)$ & $33(2.3)$ & $263(3.9)$ & & & \\
\hline Other & $39(1.1)$ & $19(1.3)$ & $266(3.9)$ & & & \\
\hline \multicolumn{7}{|l|}{ Treatment in 9 months before index date } \\
\hline Any fracture-related treatment, $\mathrm{N}(\%)^{\mathrm{a}}$ & $2,061(60.1)$ & $825(57.5)$ & $3,244(48.0)$ & 0.10 & $<0.01$ & $<0.01$ \\
\hline Cast/splint & $\mathrm{I}, 107(32.3)$ & $444(31.0)$ & $\mathrm{I}, 645(24.3)$ & 0.37 & $<0.01$ & $<0.01$ \\
\hline Application of external fixation device & $107(3.1)$ & $64(4.5)$ & $188(2.8)$ & 0.02 & 0.33 & $<0.01$ \\
\hline Closed reduction without internal fixation & $152(4.4)$ & $69(4.8)$ & $290(4.3)$ & 0.56 & 0.74 & 0.38 \\
\hline Closed reduction with internal fixation & $58(1.7)$ & $31(2.2)$ & $213(3.1)$ & 0.26 & $<0.01$ & 0.05 \\
\hline Open reduction without internal fixation & $421(12.3)$ & $148(10.3)$ & $590(8.7)$ & 0.05 & $<0.01$ & 0.05 \\
\hline Open reduction with internal fixation & $712(20.8)$ & $274(19.1)$ & $982(14.5)$ & 0.19 & $<0.01$ & $<0.01$ \\
\hline Bone graft & $80(2.3)$ & $39(2.7)$ & $103(1.5)$ & 0.43 & $<0.01$ & $<0.01$ \\
\hline Arthroscopy & $83(2.4)$ & $45(3.1)$ & $144(2.1)$ & 0.15 & 0.35 & 0.02 \\
\hline \multicolumn{7}{|l|}{ Treatment in 12 months after index date } \\
\hline Any fracture-related treatment, $\mathrm{N}(\%)^{\mathrm{a}}$ & $\mathrm{I}, 15 \mathrm{I}(33.6)$ & $605(42.2)$ & $4,077(60.3)$ & $<0.01$ & $<0.01$ & $<0.01$ \\
\hline Cast/splint & $582(17)$ & $275(19.2)$ & $\mathrm{I}, 635(24.2)$ & 0.07 & $<0.01$ & $<0.01$ \\
\hline Application of external fixation device & $48(1.4)$ & $21(1.5)$ & $152(2.2)$ & 0.86 & $<0.01$ & 0.06 \\
\hline Closed reduction without internal fixation & $46(1.3)$ & $21(1.5)$ & $87(1.3)$ & 0.74 & 0.82 & 0.59 \\
\hline Closed reduction with internal fixation & $4(0.1)$ & $3(0.2)$ & $25(0.4)$ & 0.44 & 0.02 & 0.34 \\
\hline Open reduction without internal fixation & $204(5.9)$ & $95(6.6)$ & $\mathrm{I}, 043(15.4)$ & 0.37 & $<0.01$ & $<0.01$ \\
\hline Open reduction with internal fixation & $362(10.6)$ & $199(13.9)$ & $\mathrm{I}, 640(24.2)$ & $<0.01$ & $<0.01$ & $<0.01$ \\
\hline Bone graft & $555(16.2)$ & $319(22.2)$ & $2, \mid 48(3 \mid .8)$ & $<0.01$ & $<0.01$ & $<0.01$ \\
\hline Arthroscopy & $107(3.1)$ & $53(3.7)$ & $377(5.6)$ & 0.30 & $<0.01$ & $<0.01$ \\
\hline
\end{tabular}

Notes: averall values indicate the total number of patients receiving some fracture-related treatment. The treatment groups detail the incidence of the individual treatments. Some patients may have received more than one treatment.

Abbreviations: EBGS, electrical bone growth stimulation; LIPUS, low-intensity pulsed ultrasound stimulation; No-stim, other non-stimulation fracture management interventions; SD, standard deviation.

(mean: \$16,749; median: \$7824) and LIPUS (mean: \$19,441; median $\$ 8574$ ) cohorts than in the No-stim cohort (mean: \$16,360; median: \$5548) (both $P<0.01$ ). However, total health care costs were not significantly different between the EBGS and LIPUS cohorts $(P=0.12)$ (Table 3$)$. Outpatient care, the biggest component of the total health care costs, was significantly higher in the EBGS (mean: \$9146; median: \$5417) and LIPUS (mean: \$9789; median: \$5586) cohorts than in the No-stim cohort (mean: \$8159; median: \$3967) (both $P<0.01$ ).
Fracture-related health care costs in the pre-index period were the highest in the LIPUS cohort (mean: $\$ 8749$; median: \$1089) followed by the EBGS (mean: \$7392; median: \$1223) and No-stim (mean: \$7129; median: \$893) cohorts (all pair-wise comparisons: $P<0.01$ ) (Table 3 ). Inpatient stays were the highest portion of the fracturerelated health care costs in the pre-index period. Pre-index fracture-related inpatient costs were significantly higher in the LIPUS cohort (mean: \$6258; median: \$0) than in the EBGS (mean: \$4726; median: \$0) $(P=0.02)$ and No-stim 


\begin{tabular}{|c|c|c|c|c|c|c|c|c|}
\hline 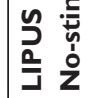 & $\begin{array}{l}\overline{0} \\
\dot{0} \\
\dot{D}\end{array}$ & o. & 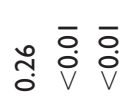 & ō & 可 & ō & $\begin{array}{l}\overline{0} \\
\dot{0} \\
\dot{V}\end{array}$ & $\overline{\mathrm{o}}$ \\
\hline 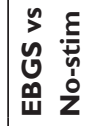 & $\begin{array}{ll}\overline{0} & 0 \\
\stackrel{0}{\circ} & \stackrel{a}{0} \\
0\end{array}$ & $\begin{array}{l}\overline{0} \\
\mathrm{~V}\end{array}$ & 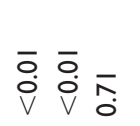 & ò & $\begin{array}{ll}\overline{0} \\
\bar{\infty} \\
0 \\
0\end{array}$ & $\begin{array}{l}\overline{0} \\
\dot{0}\end{array}$ & $\begin{array}{lll}\overline{0} & \overline{0} \\
\dot{0} & \overline{\dot{V}} \\
\dot{\mathrm{V}}\end{array}$ & סे \\
\hline 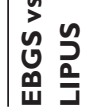 & $\simeq \stackrel{\bar{O}}{\mathrm{i}}$ & นٌ & ô & o. & 可 & ōं & $\begin{array}{l}\bar{o} \\
\dot{0} \\
\dot{v}\end{array}$ & o. \\
\hline
\end{tabular}

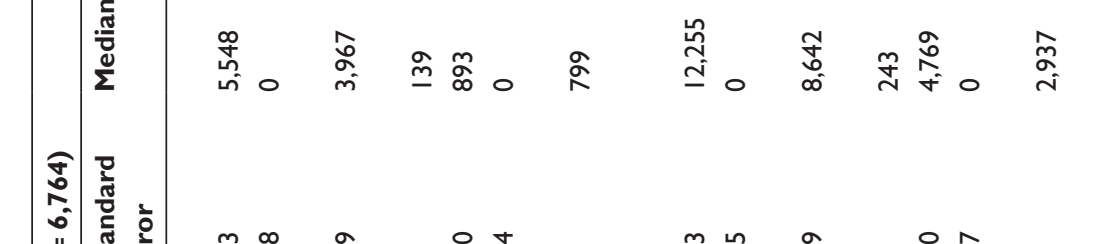

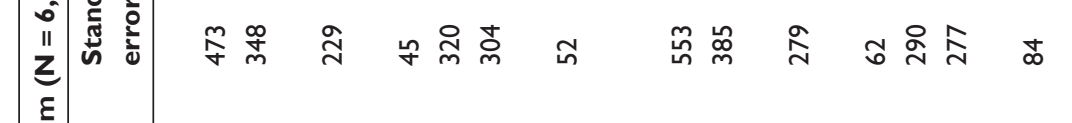

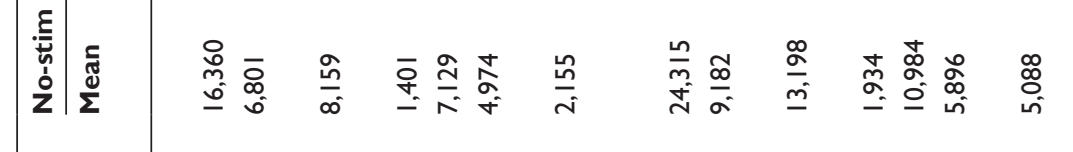

苞

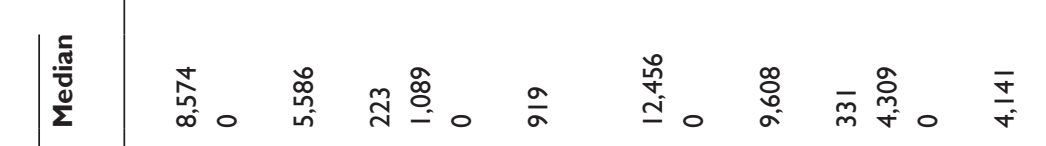

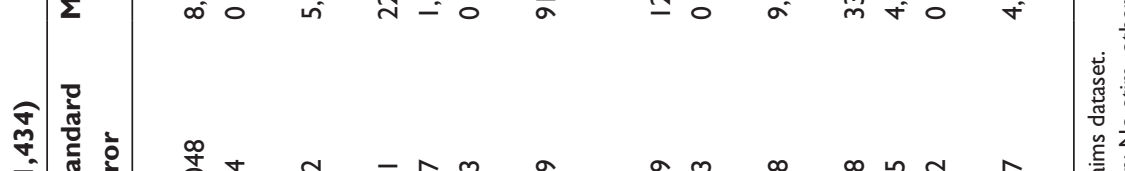

至

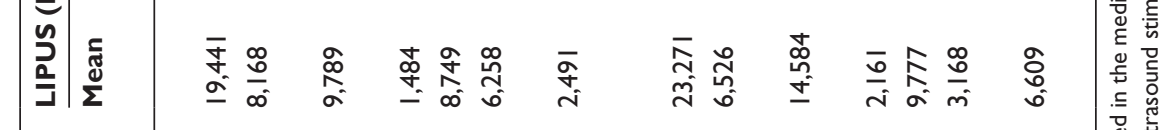

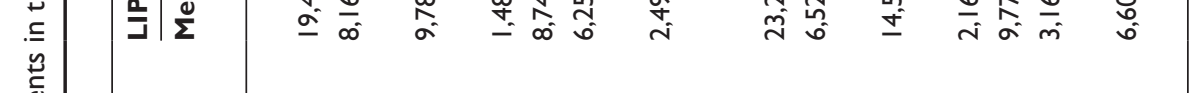

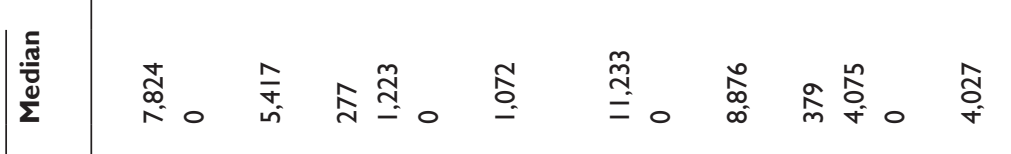

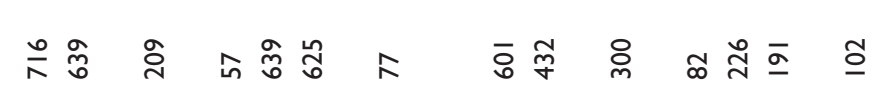

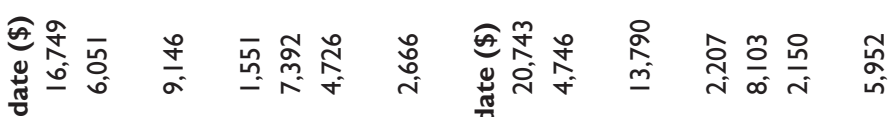

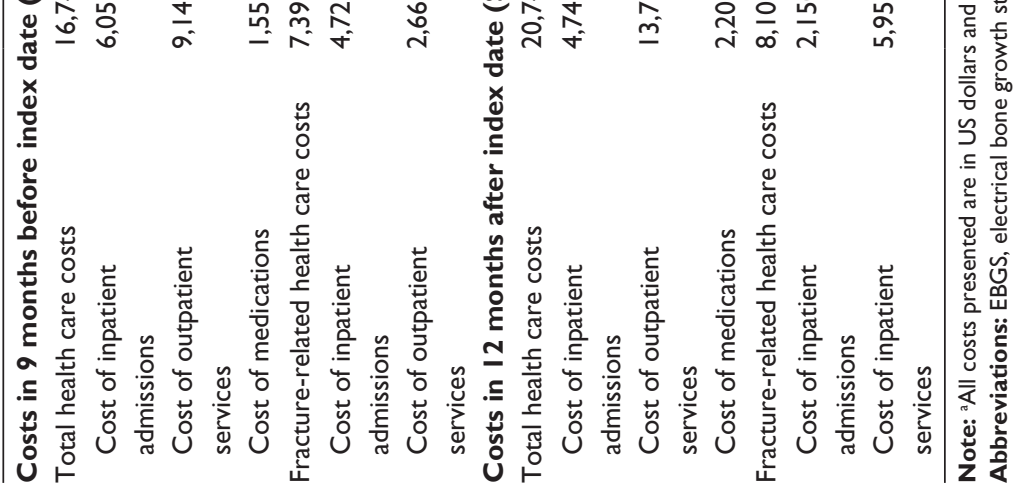


(mean: \$4974; median: \$0) $(P<0.01)$ cohorts. Additionally, the costs for fracture-related outpatient services were significantly higher in the EBGS (mean: \$2666; median: \$1072) and LIPUS (mean: \$2491; median: \$919) cohorts when compared to the No-stim (mean: \$2155; median: \$799) cohort (both $P<0.01$ ).

During the year following the first nonunion diagnosis, the total health care costs for the EBGS cohort (mean: $\$ 20,743$; median: $\$ 11,233)$ were significantly lower than the costs for the LIPUS cohort (mean: $\$ 23,271$; median: $\$ 12,456)(P<0.01)$, but not significantly different from that of the No-stim cohort (mean: $\$ 24,315$; median: $\$ 12,255)(P=0.81)$ (Table 3). The inpatient costs were the lowest in the EBGS cohort (mean: \$4746; median: \$0), followed by the LIPUS (mean: $\$ 6526$; median: \$0) and then the No-stim (mean: \$9182; median: \$0) cohorts (all pair-wise comparisons: $P<0.01$ ).

The fracture-related costs in the 12 months after the index date were the lowest in the EBGS cohort (mean: $\$ 8103$; median: \$4075), followed by the LIPUS (mean: $\$ 9777$; median: \$4309) and the No-stim (mean: \$10,984; median: $\$ 4769$ ) cohorts (all pair-wise comparisons: $P<0.01$ ). Similarly, the fracture-related inpatient costs were the lowest in the EBGS cohort (mean: \$2150; median: \$0), followed by the LIPUS (mean: $\$ 3168$; median: $\$ 0$ ) and then the No-stim (mean: \$5896; median: \$0) cohorts (all pair-wise comparisons: $P<0.01$ ). Conversely, the fracture-related outpatient costs (which includes device associated costs) were the lowest in the No-stim cohort (mean: \$5088; median: \$2937), followed by the EBGS (mean: \$5952; median: \$4027) and LIPUS (mean: \$6609; median: \$4141) cohorts (all pair-wise comparisons: $P<0.01$ ).

After controlling for demographics, CCI score, and fracture characteristics (open vs closed, treatments in the pre-index period, and fracture location), the EBGS cohort had significantly lower total health care (estimated regression coefficient $=-0.097, P<0.01$ ) and fracturerelated (estimated regression coefficient $=-0.129, P<0.01$ ) costs in the 12 months following nonunion diagnosis when compared to the No-stim cohort; whereas patients in the LIPUS cohort had similar total health care (estimated regression coefficient $=0.005, P=0.86$ ) and fracture-related (estimated regression coefficient $=-0.013, P=0.71$ ) costs to patients in the No-stim cohort (Table 4). Older age and higher CCI scores were associated with significantly higher total health care costs. Other factors associated with significantly higher total health care costs included living in the West region as compared to the South (estimated regression coefficient $=0.129, P<0.01$ ), receiving a cast $/$ splint vs no cast/splint before nonunion diagnosis (estimated regression coefficient $=0.056, P=0.01$ ), receiving open reduction vs no open reduction (estimated regression coefficient $=0.095$, $P<0.01$ ), receiving other invasive treatments including bone graft, bone marrow aspiration, arthroscopy, amputation, or implant of recombinant bone morphogenetic protein vs not (estimated regression coefficient $=0.375, P<0.01$ ), and having a fracture in the arm (estimated regression coefficient $=0.170, P<0.01$ ) or the leg (estimated regression coefficient $=0.653, P<0.01)$ vs in the foot. Similar patterns were found for fracture-related costs (Table 4).

Predicted total and fracture-related health care costs were generated based on the GLM and the regression coefficients generated in Table 4. The predicted total health care costs in the 12 months following nonunion diagnosis for the EBGS cohort $(\$ 21,632)$ were significantly lower than the No-stim (\$23,843, marginal difference: $-\$ 2211, P<0.01$ ) and the LIPUS (\$23,964, marginal difference: $-\$ 2332$, $P<0.01$ ) cohorts (Figure 2). Meanwhile, the marginal difference between the predicted total health care costs of the LIPUS and the No-stim cohorts was not significant $(\$ 121, P=0.86)$. The predicted fracture-related health care costs in the 12-month post-index period for the EBGS cohort (\$9100) were also significantly lower than the No-stim (\$10,354, marginal difference: $-\$ 1253, P<0.01$ ) and the LIPUS (\$10,225, marginal difference: $-\$ 1125, P<0.01$ ) cohorts. Alternatively, the predicted fracture-related costs for the LIPUS and the No-stim cohorts were not significantly different $(\$ 129, P=0.71)$.

\section{Discussion}

In a commercially insured US population, the majority of the patients diagnosed with a fracture nonunion received No-stim treatment, despite the presence of clinical evidence supporting the efficacy and safety of EBGS and LIPUS. ${ }^{17,26-39}$ Preclinical studies have demonstrated that EBGS increases cellular proliferation and the expression of naturally occurring growth factors including bone morphogenetic proteins to help with the bone repair process. ${ }^{46-53}$ However, due to the device cost and the limited economic evidence to compare their cost-effectiveness to other fracture management practices, bone growth stimulators have often had insurance coverage limited to a subset of the approved indications within medical policy guidelines. Over the years, the Centers for Medicare and Medicaid Services (CMS) have revised the reimbursement policy for bone growth stimulators multiple times and recently, the Agency for Healthcare Research and Quality concluded that further evaluation with randomized 
Table 4 Comparison of the total health care and fracture-related costs in the year following nonunion diagnosis ${ }^{\mathrm{a}}$

\begin{tabular}{|c|c|c|c|c|c|c|}
\hline & \multicolumn{3}{|l|}{ Total health care costs } & \multicolumn{3}{|c|}{ Fracture-related health care costs } \\
\hline & $\begin{array}{l}\text { Estimated } \\
\text { regression coefficient }{ }^{\mathrm{b}}\end{array}$ & $\begin{array}{l}\text { Standard } \\
\text { error }\end{array}$ & $P$-value & $\begin{array}{l}\text { Estimated } \\
\text { regression coefficient }{ }^{\mathrm{b}}\end{array}$ & $\begin{array}{l}\text { Standard } \\
\text { error }\end{array}$ & $P$-value \\
\hline \multicolumn{7}{|l|}{ Treatment cohort (ref: No-stim) } \\
\hline EBGS cohort & -0.097 & 0.021 & $<0.01$ & -0.129 & 0.025 & $<0.01$ \\
\hline LIPUS cohort & 0.005 & 0.028 & 0.86 & -0.013 & 0.034 & 0.71 \\
\hline \multicolumn{7}{|l|}{ Gender (ref: female) } \\
\hline Male & -0.071 & 0.019 & $<0.01$ & 0.083 & 0.023 & $<0.01$ \\
\hline \multicolumn{7}{|l|}{ Age (ref: 18-24) } \\
\hline Age 25-34 & 0.012 & 0.039 & 0.76 & -0.140 & 0.046 & $<0.01$ \\
\hline Age $35-44$ & 0.137 & 0.035 & $<0.01$ & -0.095 & 0.042 & 0.02 \\
\hline Age $45-54$ & 0.322 & 0.033 & $<0.01$ & -0.033 & 0.040 & 0.40 \\
\hline Age 55-64 & 0.381 & 0.034 & $<0.01$ & -0.008 & $0.04 I$ & 0.85 \\
\hline \multicolumn{7}{|l|}{ Region (ref: South) } \\
\hline Northeast & 0.016 & 0.031 & 0.61 & -0.001 & 0.036 & 0.98 \\
\hline North Central & 0.034 & 0.022 & 0.13 & 0.014 & 0.027 & 0.59 \\
\hline West & 0.129 & 0.025 & $<0.01$ & 0.090 & 0.030 & $<0.01$ \\
\hline Unknown & -0.127 & 0.064 & 0.05 & -0.170 & 0.076 & 0.02 \\
\hline \multicolumn{7}{|l|}{ Insurance plan type (ref: PPO) } \\
\hline Comprehensive & 0.057 & 0.050 & 0.25 & 0.010 & 0.059 & 0.86 \\
\hline EPO & -0.085 & 0.131 & 0.52 & 0.046 & 0.156 & 0.77 \\
\hline HMO & 0.011 & 0.026 & 0.67 & -0.024 & 0.031 & 0.45 \\
\hline $\mathrm{POS}^{\mathrm{c}}$ & 0.027 & 0.032 & 0.39 & -0.045 & 0.037 & 0.23 \\
\hline CDHP & 0.056 & 0.061 & 0.36 & 0.063 & 0.072 & 0.38 \\
\hline Missing/unknown & 0.088 & 0.058 & 0.13 & 0.032 & 0.068 & 0.64 \\
\hline \multicolumn{7}{|c|}{ Charlson Comorbidity Index $(\mathrm{CCl})($ ref: $\mathrm{CCl}=0)$} \\
\hline $\mathrm{CCl}=\mathrm{I}$ & 0.421 & 0.032 & $<0.01$ & 0.197 & 0.038 & $<0.01$ \\
\hline $\mathrm{CCl}=2$ & 0.432 & 0.029 & $<0.01$ & 0.234 & 0.035 & $<0.01$ \\
\hline $\mathrm{CCl}=3$ or higher & 1.057 & 0.036 & $<0.01$ & 0.487 & 0.043 & $<0.01$ \\
\hline Open fracture (ref: closed fracture) & 0.037 & 0.049 & 0.45 & 0.083 & 0.058 & 0.15 \\
\hline \multicolumn{7}{|l|}{ Treatment received in pre-index period } \\
\hline Cast/splint (ref: no cast/splint) & 0.056 & 0.021 & 0.01 & -0.037 & 0.025 & 0.13 \\
\hline $\begin{array}{l}\text { Other invasive treatment }{ }^{d} \\
\text { (ref: no other invasive treatment) }\end{array}$ & 0.375 & 0.036 & $<0.01$ & 0.459 & 0.043 & $<0.01$ \\
\hline Close reduction (ref: no close reduction) & -0.025 & 0.021 & 0.24 & -0.016 & 0.025 & 0.53 \\
\hline Open reduction (ref: no open reduction) & 0.095 & 0.026 & $<0.01$ & 0.215 & 0.031 & $<0.01$ \\
\hline \multicolumn{7}{|l|}{ Location of fracture (ref: foot) } \\
\hline Hand & -0.118 & 0.029 & $<0.01$ & 0.092 & 0.035 & 0.01 \\
\hline Arm & 0.170 & 0.024 & $<0.01$ & 0.534 & 0.028 & $<0.01$ \\
\hline Leg & 0.653 & 0.029 & $<0.01$ & 1.010 & 0.034 & $<0.01$ \\
\hline
\end{tabular}

Notes: ${ }^{\text {TT }}$ The data presented in this table were used to generate the predicted health care costs presented in Figure 2; bthe estimated regression coefficient is used as a measurement for how similar the group of interest is to the reference group. The closer to zero, the more similar the two groups are. Positive values indicate that the associated costs for the group of interest are greater than the reference group; negative values indicate that the associated costs for the group of interest are less than the reference group; 'category combines POS with and without capitation due to small sample sizes; ${ }^{d}$ other invasive treatments include bone graft, bone marrow aspiration, arthroscopy, amputation, or implant of recombinant bone morphogenetic protein.

Abbreviations: $\mathrm{CCl}$, Charlson Comorbidity Index; CDHP, consumer-directed health plan; EBGS, electrical bone growth stimulation; EPO, exclusive provider organization; $\mathrm{HMO}$, health maintenance organization; LIPUS, low-intensity pulsed ultrasound stimulation; No-stim, other non-stimulation fracture management interventions; NSAIDs, non-steroidal anti-inflammatory drugs; POS, point of service; PPO, preferred provider organization.

controlled clinical trials is needed, particularly for patients aged 65 years old or older. ${ }^{25}$ CMS's insurance coverage policy is often used as a guideline for commercial payers establishing their individual coverage policies and therefore is important to consider even for patients insured by commercial health care plans. Interestingly, while additional studies may further elucidate the benefits of bone growth stimulation, EBGS, unlike LIPUS, has existing randomized, placebo controlled nonunion studies demonstrating significantly improved healing of fracture nonunions with either capacitive coupling stimulation ${ }^{35}$ or pulsed electromagnetic field stimulation. ${ }^{36}$ Studies that compare EBGS to standard treatment practices may be helpful in supporting more extensive device coverage. Today, most commercial 


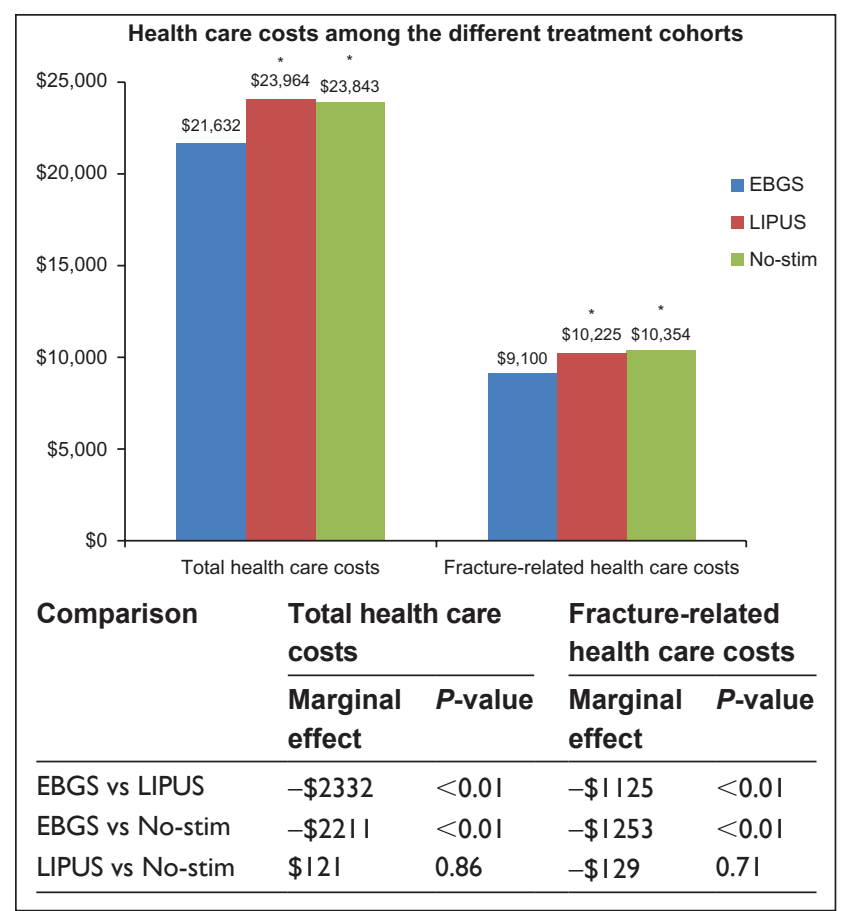

Figure 2 Comparison of total and fracture-related health care costs between the three different treatment cohorts. ${ }^{a}$

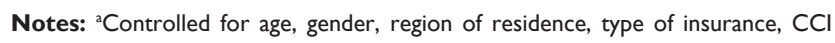
score, open fracture, fracture location, and treatments received during the preindex period, which include cast or splint use, open reduction, close reduction, and invasive treatment. *Predicted costs were significantly higher when compared to the EBGS cohort at $P<0.0$ I.

Abbreviations: $\mathrm{CCl}$, Charlson Comorbidity Index; EBGS, electrical bone growth stimulation; LIPUS, low-intensity pulsed ultrasound stimulation; No-stim, other nonstimulation fracture management interventions.

insurance plans offer coverage for EBGS devices to treat fracture nonunions. However, the coverage is often limited to certain bones and requires an elapsed timeframe before the device can be prescribed. ${ }^{54}$ Notably, this study is the first to compare actual health care utilization between EBGS, LIPUS, and No-stim treatment for fracture nonunions. Study results found that EBGS can offer significant cost-savings in the treatment of fracture nonunions when compared to both LIPUS and No-stim treatment.

Interestingly, in this study, prior to nonunion diagnosis (pre-index period), both the EBGS and LIPUS cohorts were more likely to receive fracture-related treatment, including application of external fixation devices, open reduction, or bone grafting, than the No-stim cohort, which suggests that the fractures in the stimulation cohorts were more severe and difficult to heal. In the 12 months following nonunion diagnosis, the pattern reversed, and the costs for the EBGS and the LIPUS cohorts were less than for the No-stim cohort, suggesting that stimulation treatment may be effective in managing nonunion fractures without the need for more invasive procedures. These differences in fracture management may explain the observed differences in health care costs between the different treatment cohorts. Specifically, the EBGS cohort had the lowest fracture-related costs in the 12 months following nonunion diagnosis and also the lowest costs due to inpatient admissions. The cost savings of EBGS were mainly driven by the higher savings associated with inpatient services. Notably, the fracture-related outpatient costs in the 12 months after nonunion diagnosis were significantly higher in both the EBGS and LIPUS groups when compared to the No-stim cohort. The costs of the stimulation devices, which averaged around \$3000 (EBGS: mean: \$2719, median: \$2800; LIPUS: mean: \$2626, median: \$2765), were responsible for the higher outpatient costs. Interestingly, the cost savings in the outpatient services for the No-stim group were less than that required to cover the device cost, suggesting that the No-stim patients may have also required more non-device related outpatient care than the stimulation cohorts. Despite the initial cost of the stimulation device, this study shows that patients receiving bone growth stimulators actually incur less overall treatment costs by avoiding more expensive and invasive treatments.

Due to the differences in the pre-index fracture management practices between the different treatment cohorts, a sensitivity analysis was conducted to verify that the differences in pre-index fracture management did not have an effect on required post-index fracture management. For this analysis, patients were stratified by the presence of fracturerelated inpatient stays in the pre-index period and compared for differences in post-index period health care costs. Among those patients without fracture-related inpatient stays in the pre-index period, LIPUS had significantly higher costs in the 1-year post-index period when compared to the EBGS cohort, although the costs between the No-stim and the EBGS cohorts were similar. Alternatively, among those patients with fracture-related inpatient stays in the pre-index period, No-stim incurred significantly higher costs than the EBGS cohort during the 1-year post-index period, while the costs between the LIPUS and the EBGS cohorts were comparable. This sensitivity analysis confirms that differences in preindex fracture management did not impact the observed cost savings for EBGS in the post-index period as compared to the other treatment cohorts.

Previous research has shown through economic modeling that LIPUS used in combination with conservative treatment resulted in a cost savings of over $\$ 15,000$ for patients with tibial fresh fractures. ${ }^{55,56}$ Cost savings in this model were mainly attributed to the avoidance of subsequent surgery and a reduction in workers' compensation costs. Additionally, 
part of the cost savings in the LIPUS study was attributed to a decrease in the rate of delayed unions. Alternatively, in this recent study of actual administrative claims, EBGS demonstrated an 11\%-12\% reduction in fracture-related costs compared to both LIPUS and No-stim treatment. The observed cost savings were likely due to less frequent invasive treatments required by patients in the EBGS cohort when compared to the LIPUS and No-stim cohorts. The cost savings reported in this study were not as substantial as those reported by Heckman et $\mathrm{al}^{56}$ because indirect medical costs, such as workers' compensation and disability costs, which are not available in administrative claims, were not taken into account. Notably, this study included a broad range of nonunion fractures from different anatomical locations, and used administrative claims to more accurately reflect the real-world cost savings of EBGS for health care payers and provide a direct economic comparison of the different treatment techniques.

\section{Study limitations}

In administrative claims, nonunion diagnosis is not accompanied by the diagnosis of the specific fracture. To assess the characteristics of the initial fracture, we limited our analysis to patients with fractures at a single location. In addition, we were unable to identify the fracture severity using administrative claims. Alternatively, we used the post-initial fracture management data as an indicator for fracture severity. The incidence of soft tissue damage to nearby blood vessels and nerves, the development of post-traumatic wound infection, and the presence of traumatic compartment syndrome were also assessed. The prevalence of these conditions was generally very low $(<1 \%)$ and comparable between the different treatment cohorts. For this study, the calculated fracturerelated costs were based on claims for imaging procedures of bones and claims with diagnosis/treatment codes suggesting fracture, fracture nonunion, or malunion. It is possible that these claims may relate to diagnosis or treatment of other conditions. However, it is important to note that the identified limitations apply to all treatment cohorts and therefore would not create any bias toward a specific cohort that could impact the validity of the data analysis. Notably, this study measured actual health care resource utilization and did not assess healing time or the loss of work productivity in determining health care cost savings.

\section{Conclusion}

This is the first real-world study comparing the costs associated with the treatment of fracture nonunions between EBGS,
LIPUS, and other fracture management practices (No-stim). Patients receiving EBGS for the treatment of fracture nonunions were less likely to undergo invasive procedures resulting in less health care resource use and cost savings to payers and patients. Patients receiving EGBS also had significantly less total and fracture-related costs in the year following nonunion diagnosis than patients receiving LIPUS or Nostim treatment. These study outcomes suggest that EBGS is a more cost-effective treatment for fracture nonunions when compared to both LIPUS and No-stim treatment.

\section{Acknowledgments}

The authors thank Nicole Benjamin and Alan Wang, United BioSource Corporation, Lexington, MA, USA and Lynne Coulter and Randy Graham, Biomet Spine and Bone Healing Technologies, Parsippany, NJ, USA for their contributions to this study and the preparation of this manuscript. Additionally, the authors thank Biomet Spine and Bone Healing Technologies, Parsippany, NJ, USA for providing funding support.

\section{Disclosure}

Ning Wu, Yuan-chi Lee, Teresa Wilcox, and Luke Boulanger are employees of United BioSource Corporation, which provides consulting and other research services to pharmaceutical, device, government, and non-government organizations. In their salaried positions, they work with a variety of companies and organizations, and were precluded from receiving payment or honoraria directly from these organizations for services rendered during the preparation of this manuscript. Daniel Segina is employed by Health First Physician Group and is a paid physician consultant by Biomet Spine and Bone Healing Technologies. Hallie Murray is an employee of Biomet Spine and Bone Healing Technologies, the study sponsor. The authors report no other conflicts of interest in this work.

\section{References}

1. Fayaz HC, Giannoudis PV, Vrahas MS, et al. The role of stem cells in fracture healing and nonunion. Int Orthop. 2011;35(11):1587-1597.

2. Scaphoid Non-union [webpage on the Internet]. Chicago: American Soceity for Surgery of the Hand; 2011. Available from: http://www.assh. org/Public/HandConditions/Pages/ScaphoidNon-union.aspx. Accessed November 20, 2012.

3. Orthopedics and Rehabilitation Devices Advisory Panel Meeting, Department of Health and Human Services. Food and Drug Administration, Editor. 1998. Available from: http://www.fda.gov/medicaldevices/productsandmedicalprocedures/deviceapprovalsandclearances/pmaapprovals/ucm115128.htm. Accessed February 20, 2013.

4. Electro-Biology, Inc. Bi-Osteogen System 204, PMA \#P790002. November 6, 1979. Available from: http://www.accessdata.fda.gov/ scripts/cdrh/cfdocs/cfPMA/pma.cfm. Accessed February 20, 2013. 
5. Decision Memo for Electrical Stimulation for Fracture Healing (CAG$00043 \mathrm{~N}$ ) [webpage on the Internet]. Centers for Medicare and Medicaid Services; 1999 . Available from: http://www.cms.gov/medicare-coveragedatabase $/$ details/nca-decision-memo. aspx?NCAId $=24 \&$ NCDId $=65 \& \mathrm{nc}$ $d v e r=2 \& N c a N a m e=E l e c t r i c a l+$ Stimulation + for + Fracture + Healing $\&$ IsP opup=y\&bc=AAAAAAAAEAAA\&. Accessed January 31, 2013.

6. Witten CM. Letter to Jon Caparotta. Electo-Biology, Inc. OrthoGen/ OsteoGen Implantable Bone Growth Stimulator, PMA \#P790005/S041. July 24, 1998. Available from: http://www.fda.gov/medicaldevices/ productsandmedicalprocedures/deviceapprovalsandclearances/pmaapprovals/ucm1 15128.htm. Accessed February 20, 2013.

7. Robinson CM, Court-Brown CM, McQueen MM, Wakefield AE. Estimating the risk of nonunion following nonoperative treatment of a clavicular fracture. J Bone Joint Surg Am. 2004;86-A(7):1359-1365.

8. Buijze GA, Ochtman L, Ring D. Management of scaphoid nonunion. J Hand Surg Am. 2012;37(5):1095-1100; quiz 1101.

9. Rosenberg GA, Sferra JJ. Treatment strategies for acute fractures and nonunions of the proximal fifth metatarsal. J Am Acad Orthop Surg. 2000;8(5):332-338.

10. Adams CI, Keating JF, Court-Brown CM. Cigarette smoking and open tibial fractures. Injury. 2001;32(1):61-65.

11. Calori GM, Phillips M, Jeetle S, Tagliabue L, Giannoudis PV. Classification of non-union: Need for a new scoring system? Injury. 2008;39 Suppl 2:S59-S63.

12. Giannoudis PV, MacDonald DA, Matthews SJ, Smith RM, Furlong AJ, De Boer P. Nonunion of the femoral diaphysis. The influence of reaming and non-steroidal anti-inflammatory drugs. J Bone Joint Surg Br. 2000;82(5):655-658.

13. Pountos I, Georgouli T, Calori GM, Giannoudis PV. Do nonsteroidal antiinflammatory drugs affect bone healing? A critical analysis. Scientific World Journal. 2012;2012:606404.

14. Victoria G, Petrisor B, Drew B, Dick D. Bone stimulation for fracture healing: What's all the fuss? Indian J Orthop. 2009;43(2):117-120.

15. Calori GM, Mazza E, Colombo M, Ripamonti C, Tagliabue L. Treatment of long bone non-unions with polytherapy: indications and clinical results. Injury. 2011;42(6):587-590.

16. Mayr E, Frankel V, Rüter A. Ultrasound - an alternative healing method for nonunions? Arch Orthop Trauma Surg. 2000;120(1-2):1-8.

17. Dahabreh Z, Calori GM, Kanakaris NK, Nikolaou VS, Giannoudis PV. A cost analysis of treatment of tibial fracture nonunion by bone grafting or bone morphogenetic protein-7. Int Orthop. 2009;33(5):1407-1414.

18. Richmond J, Colleran K, Borens O, Kloen P, Helfet DL. Nonunions of the distal tibia treated by reamed intramedullary nailing. $J$ Orthop Trauma. 2004;18(9):603-610.

19. EBI Bone Healing System ${ }^{\circledR}$ original PMA (P790002) and current model PMA (P790002/S22). Available from: http://www.accessdata.fda.gov/ scripts/cdrh/cfdocs/cfPMA/pma.cfm. Accessed February 20, 2013.

20. Biomet ${ }^{\circledR}$ OrthoPak $^{\circledR}$ Non-Invasive Bone Growth Stimulator System original PMA (P850022) and current model PMA (P850022/S017). Available from: http://www.accessdata.fda.gov/scripts/cdrh/cfdocs/ cfPMA/pma.cfm. Accessed February 20, 2013.

21. Exogen ${ }^{\circledR}$ Ultrasound Bone Healing System PMA (900009/S06). Available from: http://www.accessdata.fda.gov/scripts/cdrh/cfdocs/cfPMA/ pma.cfm. Accessed February 20, 2013.

22. OrthoFix ${ }^{\circledR}$ Physio-Stim ${ }^{\circledR}$ Bone Growth Stimulator original PMA (P850007) and current model PMA (P850007/S020). Available from: http://www.accessdata.fda.gov/scripts/cdrh/cfdocs/cfPMA/pma.cfm. Accessed February 20, 2013.

23. DJO ${ }^{\mathrm{TM}}$ Global CMF OL1000 ${ }^{\mathrm{TM}}$ Bone Growth Stimulator original PMA (P910066) and current model PMA (P910066/S023/S024). Available from: http://www.accessdata.fda.gov/scripts/cdrh/cfdocs/cfPMA/pma. $\mathrm{cfm}$. Accessed February 20, 2013.

24. Bone Growth Stimulators [webpage on the Internet]. St Paul: Minnesota Department of Human Services; 2011 [updated July 28, 2011]. Available from: http://www.dhs.state.mn.us/main/idcplg?IdcService=GET_ DYNAMIC_CONVERSION\&dDocName=dhs16_149902\&Revision SelectionMethod=LatestReleased. Accessed May 2, 2012.
25. ECRI Evidence-based Practice Center. The Role of Bone Growth Stimulating Devices and Orthobiologics in Healing Nonunion Fractures. Rockville, USA Department of Health and Human Services; 2005. Available from: https://www.ecri.org/Documents/EPC/ Role_of_Bone_Growth_Stimulating_Devices_and_Orthobiologics_in_ Healing_Nonunion_Fracture.pdf. Accessed January 31, 2013.

26. Adams BD, Frykman GK, Taleisnik J. Treatment of scaphoid nonunion with casting and pulsed electromagnetic fields: a study continuation. J Hand Surg Am. 1992;17(5):910-914.

27. Bassett CA, Mitchell SN, Gaston SR. Treatment of ununited tibial diaphyseal fractures with pulsing electromagnetic fields. J Bone Joint Surg Am. 1981;63(4):511-523.

28. Brighton CT, Pollack SR. Treatment of nonunion of the tibia with a capacitively coupled electrical field. J Trauma. 1984;24(2):153-155.

29. Brighton CT, Pollack SR. Treatment of recalcitrant non-union with a capacitively coupled electrical field. A preliminary report. J Bone Joint Surg Am. 1985;67(4):577-585.

30. Brighton CT, Shaman P, Heppenstall RB, Esterhai JL Jr, Pollack SR, Friedenberg ZB. Tibial nonunion treated with direct current, capacitive coupling, or bone graft. Clin Orthop Relat Res. 1995;321: 223-234.

31. Dunn AW, Rush GA 3rd. Electrical stimulation in treatment of delayed union and nonunion of fractures and osteotomies. South Med J. 1984;77(12):1530-1534.

32. Frykman GK, Taleisnik J, Peters G, et al. Treatment of nonunited scaphoid fractures by pulsed electromagnetic field and cast. $J$ Hand Surg Am. 1986;11(3):344-349.

33. Holmes GB Jr. Treatment of delayed unions and nonunions of the proximal fifth metatarsal with pulsed electromagnetic fields. Foot Ankle Int. 1994;15(10):552-556.

34. Kooistra BW, Jain A, Hanson BP. Electrical stimulation: Nonunions. Indian J Orthop. 2009;43(2):149-155.

35. Marcer M, Musatti G, Bassett CA. Results of pulsed electromagnetic fields (PEMFs) in ununited fractures after external skeletal fixation. Clin Orthop Relat Res. 1984;190:260-265.

36. Meskens MW, Stuyck JA, Feys H, Mulier JC. Treatment of nonunion using pulsed electromagnetic fields: a retrospective follow-up study. Acta Orthop Belg. 1990;56(2):483-488.

37. Scott G, King JB. A prospective, double-blind trial of electrical capacitive coupling in the treatment of non-union of long bones. $J$ Bone Joint Surg Am. 1994;76(6):820-826.

38. Sharrard WJ. A double-blind trial of pulsed electromagnetic fields for delayed union of tibial fractures. J Bone Joint Surg Br. 1990;72(3): 347-355.

39. Sharrard WJ, Sutcliffe ML, Robson MJ, Maceachern AG. The treatment of fibrous non-union of fractures by pulsing electromagnetic stimulation. J Bone Joint Surg Br. 1982;64(2):189-193.

40. Busse JW, Kaur J, Mollon B, et al. Low intensity pulsed ultrasonography for fractures: systematic review of randomised controlled trials. BMJ. 2009;338:b351.

41. Kanakaris NK, Giannoudis PV. The health economics of the treatment of long-bone non-unions. Injury. 2007;38 Suppl 2:S77-S84.

42. Truven Health Analytics [webpage on the Internet]. Databases and Online Tools. Ann Arbor: Truven Health Analytics. Available at: http:// www.truvenhealth.com/your_healthcare_focus/pharmaceutical_and_ medical_device/data_databases_and_online_tools.aspx. Accessed January 6, 2013.

43. D'Hoore W, Bouckaert A, Tilquin C. Practical considerations on the use of the Charlson comorbidity index with administrative data bases. J Clin Epidemiol. 1996;49(12):1429-1433.

44. Rubino M, Summers KH, Puenpatom A, Fu C, Ohsfeldt RL, Ben-Joseph RH. A comparison of daily average consumption (DACON) of oxycodone and oxymorphone long-acting oral tablets. J Manag Care Pharm. 2011;17(5):367-376.

45. Consumer Price Index [webpage on the Internet]. Washington: Bureau of Labor Statistics. Available at: http://www.bls.gov/cpi/. Accessed October 26, 2012. 
46. Aaron RK, Wang S, Ciombor DM. Upregulation of basal TGFbeta1 levels by EMF coincident with chondrogenesis - implications for skeletal repair and tissue engineering. J Orthop Res. 2002;20(2):233-240.

47. Bodamyali T, Bhatt B, Hughes FJ, et al. Pulsed electromagnetic fields simultaneously induce osteogenesis and upregulate transcription of bone morphogenetic proteins 2 and 4 in rat osteoblasts in vitro. Biochem Biophys Res Commun. 1998;250(2):458-461.

48. Brighton CT, Wang W, Seldes R, Zhang G, Pollack SR. Signal transduction in electrically stimulated bone cells. J Bone Joint Surg Am. 2001; 83-A(10):1514-1523.

49. Guerkov HH, Lohmann CH, Liu Y, et al. Pulsed electromagnetic fields increase growth factor release by nonunion cells. Clin Orthop Relat Res. 2001;384:265-279.

50. Lorich DG, Brighton CT, Gupta R, et al. Biochemical pathway mediating the response of bone cells to capacitive coupling. Clin Orthop Relat Res. 1998;350:246-256.

51. Tepper OM, Callaghan MJ, Chang EI, et al. Electromagnetic fields increase in vitro and in vivo angiogenesis through endothelial release of FGF-2. FASEB J. 2004;18(11):1231-1233.
52. Wang Z, Clark CC, Brighton CT. Up-regulation of bone morphogenetic proteins in cultured murine bone cells with use of specific electric fields. J Bone Joint Surg Am. 2006;88(5):1053-1065.

53. Zhuang H, Wang W, Seldes RM, Tahernia AD, Fan H, Brighton CT. Electrical stimulation induces the level of TGF-beta1 mRNA in osteoblastic cells by a mechanism involving calcium/calmodulin pathway. Biochem Biophys Res Commun. 1997;237(2):225-229.

54. Huang AJ, Gemperli MP, Bergthold L, Singer SS, Garber A. Health plans' coverage determinations for technology-based interventions: the case of electrical bone growth stimulation. Am J Manag Care. 2004;10(12):957-962.

55. Button ML, Sprague S, Gharsaa O, Latouche S, Bhandari M. Economic evaluation of bone stimulation modalities: A systematic review of the literature. Indian J Orthop. 2009;43(2):168-174.

56. Heckman JD, Sarasohn-Kahn J. The economics of treating tibia fractures. The cost of delayed unions. Bull Hosp Jt Dis. 1997;56(1):63-72.
Orthopedic Research and Reviews

\section{Publish your work in this journal}

Orthopedic Research and Reviews is an international, peer-reviewed, open access journal focusing on the patho-physiology of the musculoskeletal system, trauma, surgery and other corrective interventions to restore mobility and function. Advances in new technologies, materials, techniques and pharmacological agents are particularly welcome. The journal welcomes

\section{Dovepress}

original research, clinical studies, reviews \& evaluations, expert opinion and commentary, case reports and extended reports. The manuscript management system is completely online and includes a very quick and fair peer-review system, which is all easy to use. Visit http://www.dovepress. com/testimonials.php to read real quotes from published authors. 